\title{
ARIEL Y LA PREGUNTA POR LA IDENTIDAD LATINOAMERICANA
}

\author{
María Eugenia Vázquez Semadeni*
}

\begin{abstract}
RESUMEN: Se realiza un recorrido historiográfico por las mutaciones de los referentes para la construcción de la identidad latinoamericana a partir de la publicación del Ariel de Rodó. Se analizan sus cambios de valoración y de sentido, en gran medida determinados históricamente. Se destaca la lectura actual, a partir de las variaciones en el concepto de cultura, la ruptura de las formas tradicionales de conocimiento y la reivindicación de la diferencia. Se revisa el papel del intelectual latinoamericano y la vigencia de la triada shakesperiana.
\end{abstract}

PALABRAS CLAVE: Identidad latinoamericana, Complejo simbólico, Intelectual, Cultura.

ABSTRACT: A historiographic revision is presented about the transformations suffered by the referents for the construction of the Latin American identity since the publication of Rodó's Ariel. An analysis of the historically-driven changes on the appreciation of the characters is also presented, emphasizing the current perception of the complex, starting from the change in the concept of culture, the breakdown of the traditional forms of knowledge, and the vindication of the difference. A review of the role of the Latin American intellectual, and about the validity of the Shakespearian triad is given.

KEY WORDS: Latin American identity, Symbolic complex, Intellectual, Culture.

\section{INTRODUCCIÓN}

La pregunta por la identidad latinoamericana dista mucho de ser nueva, puede remontarse hasta el siglo XVI cuando los españoles americanos fueron tomando conciencia de sí mismos como americanos ante el despojo del que se sentían objeto por parte de los peninsulares. ${ }^{1}$ Más tarde, casi inmediatamente después de la consecución de las independencias de los

\footnotetext{
*Colegio de Michoacán (msemadeni@colmich.edu.mx).

${ }^{1}$ David Brading, Los orígenes del nacionalismo mexicano, trad. de Soledad Loaeza, México, Era, 1980, pp. 15-23.
} 
estados latinoamericanos, Simón Bolívar propuso crear un organismo que vinculara a los nuevos países. Esta propuesta no era inocente; durante los siglos de dominación española no existían entidades territoriales que dieran sustento al surgimiento de esos nuevos países, por lo que para el pensamiento de muchos las divisiones geopolíticas que aparecieron después de la independencia sólo habían venido a separar lo que durante siglos había estado unido. Por ello, esta pregunta por la identidad latinoamericana ha persistido, latente o actuante, y ha guiado explícita o implícitamente el pensamiento de muchos intelectuales hispanoamericanos.

Cabría preguntarse si hoy, en pleno siglo XXI, ante una inminente "globalización" que tiende a la desterritorialización y frente al avance casi irrefrenable de los proyectos económicos de las grandes potencias mundiales, con sus evidentes implicaciones políticas y sociales, sigue teniendo sentido la búsqueda de una identidad, ya sea local, nacional o supranacional. A lo largo del siglo XIX comenzaron a surgir voces que pretendían encontrar elementos que identificaran a los países del Sur, en oposición a la América sajona. A finales del siglo XIX y sobre todo a principios del xx, la pregunta por la identidad latinoamericana encontró, no casualmente, su referente simbólico en La Tempestad de Shakespeare, en particular en las figuras de Ariel y Calibán. El contenido significativo de estos símbolos no ha permanecido estático, ha sido actualizado y resignificado a lo largo del siglo y ha ido adquiriendo nuevos sentidos de acuerdo con el acontecer histórico. Por otro lado, en la actualidad, con todas las nuevas tendencias del análisis cultural que se fundan justamente en la reivindicación de la diferencia y la valoración de la diversidad, se cuestionan por una parte los referentes monosimbólicos que tienden a una falsa unificación, pero por otra parte adquiere una nueva dimensión la pregunta por la identidad, pues se intenta que el otro deje de ser el referente para la construcción de lo que se es y se haga posible el hablar desde sí mismo.

Dentro de este complejo panorama, el enorme número de posturas que se han adoptado respecto al problema de la identidad latinoame- 
ricana y a su referente simbólico shakesperiano, la aparentemente infinita cantidad de publicaciones que existen al respecto, el notable número de congresos, coloquios y simposios dedicados al tema o a otros con él relacionados, y las incontables preguntas, más que respuestas, que de él se han derivado, si algo muestran es la pasión que aún sigue despertando y la importancia que tiene para las culturas hispanoamericanas, pues incluso al negarle vigencia se le otorga preeminencia. Por ello, en este trabajo se realiza un recorrido historiográfico, muy breve, sobre la forma en que se ha entendido el problema de la identidad latinoamericana desde la perspectiva de algunos de sus principales intelectuales; se buscará ubicar sobre qué bases se ha intentado construir dicha identidad a partir del Ariel de Rodó y se tratará de delinear la ruta que han seguido los desplazamientos valorativos de que ha sido objeto el complejo simbólico de La Tempestad en América Latina, preguntándose particularmente por el sentido que tiene o puede tener en la actualidad, por su vigencia y validez, así como por su capacidad de ofrecer posturas posibles frente a los procesos globalizadores.

\section{RODÓ Y EL ARIEL}

Cuando a principios del siglo xx José Enrique Rodó publicó su Ariel, la situación económica y política de América Latina era crítica. A lo largo del siglo XIX, pero sobre todo durante la segunda mitad, la mayoría de los gobiernos de las jóvenes naciones había intentado imponer un sistema liberal cuyo modelo prácticamente indiscutible era el estadounidense. Según O'Gorman dicho modelo no funcionó y más bien condujo a una realidad inoperante en la que el traslado de las instituciones norteamericanas a los países latinoamericanos no produjo los resultados esperados. ${ }^{2}$

Que haya sido realmente un fracaso, o sus causas, puede ser muy discutible, pero no lo es tanto el que rápidamente la "formidable república del Norte" pasó de ser objeto de admiración e imitación a convertirse en

\footnotetext{
${ }^{2}$ Edmundo O’Gorman, México: el trauma de su historia, México, UNAM, 1977, p. 41.
} 
la causa del fracaso latinoamericano, es decir, en el enemigo cuyos intereses maquiavélicos impidieron el desarrollo de los nuevos países. Dicha visión se derivó de que durante las últimas décadas del siglo XIX el intervencionismo político y el expansionismo comercial estadounidense sobre Hispanoamérica se habían hecho evidentes, desplazando paulatinamente la injerencia política y económica de los países europeos. La situación se intensificó a partir de la lucha cubana por su independencia de España, en la que la intervención de Estados Unidos y el "imperialismo informal"3 que logró imponer en Cuba pusieron a las élites latinoamericanas en una situación ambivalente: por una parte apoyaban y veían con simpatía la independencia cubana de España, pero también temían la creciente influencia y el evidente poderío militar de Estados Unidos.

Los Estados Unidos no sólo se apoderaron de Cuba y Puerto Rico, sino que iniciaron su penetración en el Océano Pacífico a través de Filipinas y lanzaron su tentáculo hasta Centroamérica, mediante la artificial creación de Panamá como nación independiente para facilitar la construcción del famoso canal. Es, pues, legítimo hablar, como ya lo ha hecho algún estudioso, del año 1898 como una "divisoria de aguas" que anuncia un nuevo orden internacional para el siglo que está a la puerta. ${ }^{4}$

De este modo, Estados Unidos dejó de ser el modelo y se convirtió en una amenaza inminente para los “jóvenes y débiles” países latinoamericanos. Por otra parte, esta situación generó una revaloración del pasado hispánico y de los sistemas tradicionales, en oposición a los de la modernidad representados por Estados Unidos. En medio de todo este contexto aparece el Ariel de José Enrique Rodó.

\footnotetext{
${ }^{3}$ Este término se emplea para hacer referencia al control a través de tratados comerciales, con la cláusula de nación más favorecida, y mediante la instalación de gobiernos estables, de acuerdo con lo señalado por Walther L. Bernecker, "El fin de siglo en el Río de la Plata: intereses internacionales y reacciones latinoamericanas", en Ottmar Ette y Titus Heydenreich [eds.], José Enrique Rodó y su tiempo. Cien años de Ariel, Frankfurt/Madrid, Vervuet/Iberoamericana, 2000, p. 28.

${ }^{4}$ José Luis Abellán, "Modernismo: Ariel como símbolo", Anales del Seminario de Historia de la Filosofía, núm. 17, Madrid, 2000, p. 220.
} 
En su obra es clara la búsqueda de identidad latinoamericana, a la cual pretendía fundamentar en la herencia clásica, cimentada en los valores espirituales, en la cultura (que él entiende como la "alta cultura" principalmente) y en particular en la lengua. Para Rodó:

Ariel es el imperio de la razón y el sentimiento sobre los bajos estímulos de la irracionalidad; es el entusiasmo generoso, el móvil alto y desinteresado en la acción, la espiritualidad de la cultura, la vivacidad y la gracia de la inteligencia, el término ideal a que asciende la selección humana, rectificando en el hombre superior los tenaces vestigios de Calibán, símbolo de sensualidad y de torpeza, con el cincel perseverante de la vida. ${ }^{5}$

Intenta guiar a la juventud latinoamericana por el camino del espiritualismo y el cultivo de los valores morales, representados en su numen, Ariel, para defenderse de la amenaza del utilitarismo y materialismo que define a la sociedad estadounidense. Propone escapar de la esclavitud material salvando la libertad interior de la razón y el sentimiento.

Contrario a lo que se sostuvo después, y que se abordará más adelante, la postura de Rodó no es resultado del resentimiento, él no propone una cruzada latinoamericana en contra de Estados Unidos, sino simplemente ofrece a Ariel como un escudo espiritual para defenderse del avance del utilitarismo calibanesco: "Yo os ruego que os defendáis, en la milicia de la vida, contra la mutilación de vuestro espíritu por la tiranía de un objetivo único e interesado."

Por sus constantes alusiones a Renan, se ha considerado a éste como la principal referencia en la obra de Rodó, aunque rechaza la postura antidemocrática de aquél, al considerar que la democracia implica la posibilidad de acceso de todos al conocimiento de la virtud para crear nuevas jerarquías sociales basadas en la "verdadera" superioridad, es decir, en

${ }^{5}$ José Enrique Rodó y Roberto Fernández Retamar, Ariel y Calibán. Apuntes sobre la cultura en nuestra América, pról. y notas de Abelardo Villegas, México, SEP/UnAM, 1982, p. 13.

${ }^{6}$ Ibid., p. 25. 
la superioridad de los mejores. Lo que debe evitarse es que la democracia lleve a un igualitarismo vacío, para lo cual se requiere la "educación de la democracia y su reforma”.

Racionalmente concebida, la democracia admite siempre un imprescriptible elemento aristocrático, que consiste en establecer la superioridad de los mejores, asegurándola sobre el consentimiento libre de los asociados. Ella consagra, como las aristocracias, la distinción de calidad; pero las resuelve a favor de las calidades realmente superiores - las de la virtud, el carácter, el espíritu-, y sin pretender inmovilizarlas en clases constituidas aparte de las otras, que mantengan a su favor el privilegio execrable de la casta, renueva sin cesar su aristocracia dirigente en las fuentes vivas del pueblo y la hace aceptar por la justicia y el amor. ${ }^{7}$

Una democracia como ésta logrará la conciliación de la herencia cristiana de igualdad con la herencia clásica del orden, la jerarquía y el respeto del genio. Por eso era indispensable que América Latina se protegiera de la creciente admiración que despertaba la "formidable república del Norte", es decir, de la "nordomanía", pues su democracia estaba cimentada en el utilitarismo y la inmediatez de las necesidades materiales, carecía de refinamiento y espiritualidad, y por lo tanto adoptarla por imitación llevaría a la absoluta mediocridad. Si en Latinoamérica se aplicaban los modelos norteamericanos se caería en la desnaturalización de su carácter, pues aunque reconoce la ausencia de un sello propio y definido en los pueblos latinoamericanos, sostiene la existencia de "una herencia de raza, una gran tradición étnica"8 que debía mantenerse como vínculo sagrado de América Latina, sin por ello negar el cosmopolitismo.

Como puede verse, para Rodó es claro que las instituciones norteamericanas no pueden sin más trasladarse a los países latinoamericanos y esperar que funcionen adecuadamente, pues el ser de estos pueblos está determinado por su historia y es radicalmente distinto. Por ello, Latinoamérica debe realizar una sabia labor de síntesis, que tome lo mejor

\footnotetext{
${ }^{7}$ Ibid., p. 46.

${ }^{8}$ Ibid., p. 51.
} 
de la tradición clásica e hispánica y sepa valorar lo bueno del ejemplo de la América anglosajona, de modo que "la obra del positivismo norteamericano servirá a la causa de Ariel, en último término", pues "Ariel triunfante, significa idealidad y orden en la vida, noble inspiración en el pensamiento, desinterés en moral, buen gusto en arte, heroísmo en la acción, delicadeza en las costumbres", y aun

vencido una y mil veces por la indomable rebelión de Calibán, proscripto por la barbarie vencedora, asfixiado por el humo de las batallas, manchadas las alas transparentes al rozar el "eterno estercolero de Job", Ariel resurge inmortalmente, Ariel recobra su juventud y su hermosura, y acude ágil, como al mandato de Próspero, al llamado de cuantos le aman e invocan en la realidad. ${ }^{9}$

La América que comienza en el Río Grande es el sitio destinado a cultivar la espiritualidad clásica, y su raza, merecedora de egregio destino, la encomendada a realizar esta ilustre tarea; por ello Rodó puede cerrar su ensayo con una visión utópico-profética llena de orgullo y esperanza: "Yo suelo embriagarme con el sueño del día en que las cosas reales harán pensar que la Cordillera que se yergue sobre el suelo de América ha sido tallada para ser el pedestal definitivo de esta estatua [la de Ariel], para ser el ara inmutable de su veneración." ${ }^{10}$ Lo que Rodó propone es, más que un proyecto político, uno cultural, que ponga el acento en los valores espirituales, estéticos y religiosos, y de lo que sería símbolo Ariel sería de ese proyecto. ${ }^{11}$

Así en el contexto de la amenaza del intervencionismo estadounidense de principios del siglo Xx la idea de la identidad latinoamericana simbolizada en Ariel se convierte en el referente utópico mediante el cual, a partir de ese momento, se opondrá resistencia a los embates norteamericanos y se intentará preservar los valores tradicionales heredados de España.

\footnotetext{
${ }^{9}$ Ibid., pp. 73-74.

${ }^{10}$ Ibid., p. 75.

${ }^{11}$ Abelardo Villegas, Prólogo a Fernández Retamar, op. cit., p. 1.
} 
Con lo hasta ahora mencionado puede hablarse de la existencia de una doble dimensión en el pensamiento rodoniano: la identidad latinoamericana es sin duda un referente utópico, un ideal a alcanzar, como ya se dijo un proyecto cultural; no obstante, esta utopía tiene un sustento real claro y conciso que es la historia, el pasado colonial, la herencia hispánica que se traduce en la lengua, en la religión, en las costumbres y sobre todo en la espiritualidad. No puede negarse, sin embargo, que se trata de una identidad cultural de élite que pretendía construirse a expensas de la compleja realidad latinoamericana, buscando eliminar la diferencia en aras de uniformar a las poblaciones de América Latina en función de aquello que la élite intelectual, que no necesariamente la política, consideraba valioso.

La importancia de Ariel para la construcción de la identidad latinoamericana fue definitiva, porque contribuyó a centrar los elementos del discurso, colocando a Estados Unidos como el enemigo y el causante del atraso y definiendo como el elemento de cohesión a la herencia clásica. Rodó, por encima de todo, aportó la idea de que existía una unidad inherente a América Latina que se superponía a las diversidades nacionales, y contribuyó a la definición de las formas simbólicas que expresarían la búsqueda de los elementos identitarios para ese gran complejo supranacional.

Aunque apenas dos años antes de la publicación de Ariel Rubén Darío había empleado ya los referentes simbólicos de La Tempestad para aludir al mismo problema, ${ }^{12}$ es sin duda la obra de Rodó la que obtiene mayores alcances y llega a ser tomada como manifiesto por los "arielistas", quienes radicalizan esta postura y perfilan de manera definitiva la lucha por la identidad latinoamericana en oposición al enemigo, es decir, a Estados Unidos. En este sentido, esa pretendida identidad no se intenta construir a partir de lo que se es, sino en función de lo que no se es: no se es Estados Unidos, no se puede, ni se debe querer ser como él, sino

${ }^{12}$ Cfr. Rubén Darío, "El triunfo de Calibán”, Proyecto ensayo hispánico, Georgia. En http://ensayo.rom.uga.edu/antología/XIXA/darío/ [Consulta: diciembre, 2003]. 
que debe asumirse y construirse el propio ser a partir de la propia realidad y, sobre todo, a partir de la propia historia, que es el elemento común y por lo tanto, el factor de cohesión que permitirá la anhelada unidad.

En la radicalización de los arielistas, que convirtieron la obra de Rodó en el "Evangelio de la Esperanza", puede verse también una doble vertiente, por una parte la necesidad de autoafirmarse a partir de algo que se percibe pero que también debe construirse, la pretendida identidad cultural, y por otra parte el resentimiento que se había generado contra Estados Unidos, resentimiento que a su vez se construye a partir de varios elementos: el rencor que despertaban los logros, los avances económicos, políticos, sociales de los norteamericanos que los países latinoamericanos no habían logrado alcanzar; el resentimiento derivado de la falta de apoyo que se sentía de parte de Estados Unidos, pues consideraban que este país tenía la "obligación moral" de ayudar a sus hermanos americanos a liberarse del yugo europeo y salir adelante sobre todo en el ámbito económico; y el rencor porque lejos de haber cumplido sus expectativas como modelo y ejemplo a seguir se había convertido en el nuevo enemigo por sus constantes intervenciones en América Latina. Así, al sentirse impotentes contra el poderoso enemigo, el resultado del resentimiento es un envanecimiento que los hace creerse superiores en el ámbito espiritual, aunque con pesar se reconocen inferiores en el económico, militar y político. Esto los lleva a colocar en el enemigo todos los males y olvidarse de su propia parte de culpa en el fracaso de los proyectos nacionales latinoamericanos..$^{13}$

La postura elitista y hasta cierto punto conservadora de Rodó le acarreó múltiples críticas; además, en algunos de los casos el radicalismo de los arielistas fue tal que llegaron a adoptar una postura estatista y antidemocrática, expresada por ejemplo en el Calibán rex (1914) de José Antonio Ramos o en Calibán: tragicomedia de la vida politica (1943), de

${ }^{13}$ O'Gorman, op . cit., passim. Conrado Hernández, "Edmundo O'Gorman y el liberalismo mexicano", Metapolítica, vol. 7, núm. 31, México, septiembre-octubre, 2003, p. 111 . 
Manuel Gálvez, que identificaba a Calibán con las "masas” que "ocasionaban” los conflictos sociales y políticos de los países latinoamericanos.

En las primeras décadas del siglo se extrema la alarma de los intelectuales de la ciudad letrada frente a la plebe urbana, las luchas obreras y la insurgencia campesina. Encontraremos entonces numerosas reescrituras autoritarias de The Tempest y una suerte de regreso de lo reprimido que Calibán nombra. El arielismo se perfila como una serie de posicionamientos discursivos frente a las "muchedumbres democráticas" o masas, categoría con la que - como recuerda Raymond Williams - el poder se desencuentra frente a lo popular. Con razón Luis Alberto Sánchez (1900-1994) señalaba que en la mayoría de los casos el arielismo después de Rodó consistió en un esteticismo acomodado en los beneficios de la política y los negocios con el Estado, pelechando en el regazo de "caudillos bárbaros" y coqueteándole al fascismo. ${ }^{14}$

Por ello, y con la incorporación del pensamiento marxista, pronto varios autores latinoamericanos, como José Carlos Mariátegui y Fernando Díez de Medina, comprometidos con la tradición indígena, con los grupos populares y con una postura antielitista comienzan a criticar el idealismo de Rodó y a considerar obsoleto el arielismo, proponiendo nuevas vías de interpretación e incluso el reemplazo de las formas simbólicas shakesperianas. ${ }^{15}$

Una de las principales críticas a Rodó fue la elaborada por Edmundo O'Gorman, quien señala que Rodó destaca la superioridad espiritual de América Latina, cuyo estatuto ontológico es totalmente distinto al de la América sajona, por lo que intentar imitarla no sólo es infructuoso, sino carece de razón de ser. De este modo, se oculta el fracaso latinoamericano y se traduce en una autoglorificación que se transforma en utopía, cimentada en la unidad que llevará al triunfo y a la exaltación de los sistemas de creen-

${ }^{14}$ Carlos Jáuregui, "Calibán: ícono del 98. A propósito de un artículo de Rubén Darío]“, Proyecto ensayo hispánico. Georgia.

En http://ensayo.rom.uga.edu/filosofos/nicaragua/dario/Jauregui.htm [Consulta: diciembre, 2003].

15 Ibid., passim. 
cias y valores heredados de la Colonia. Pero esta utopía, que como tal debería ser dinámica y proyectarse a futuro, finalmente se convierte en un mito estático y que sólo remite al pasado, y que lleva a la intelectualidad latinoamericana a proclamar el espíritu idealista de América Latina, en oposición al espíritu pragmático de la sajona. El problema de esta postura es que si Latinoamérica no quiere contaminarse del utilitarismo norteamericano tendría que vivir prácticamente aislada de los procesos mundiales, y si quiere ser partícipe de ellos no puede evitar "calibanizarse". ${ }^{16}$

\section{CALIBÁN}

A pesar de las críticas y el rechazo, el referente de La Tempestad permaneció, aunque con sus inevitables matices, y con el transcurrir del siglo el símbolo de la identidad latinoamericana se fue trasladando de Ariel a Calibán, entendido éste, primero, como el colonizado y más tarde como el mestizo. Así, de un Calibán que a principios del siglo xx representaba un ser inculto, salvaje y bárbaro (cuya identificación con Estados Unidos implicaba una clara inversión de las categorías de Sarmiento y por lo tanto una crítica a los proyectos civilizadores del siglo $\mathrm{XIX}^{17}$ ) se pasó a un Calibán que simbolizaba primero al habitante nativo, dueño original de la isla, dominado por el saber de Próspero, y de éste al mestizo, resultado único y original de la mezcla producida por la colonización, pero que valoraba mucho más al elemento indígena y nativo que al hispánico. Con ello se dio un importante desplazamiento de una identidad construida sobre elementos culturales a una identidad cimentada en aspectos principalmente de raza.

${ }^{16}$ O'Gorman, op. cit., pp. 59-81.

${ }^{17}$ Cfr. Liliana Weinberg, "La identidad como traducción. Itinerario del Calibán en el ensayo latinoamericano", Estudios interdisciplinarios de América Latina y el Caribe, vol. 5, núm. 1, Tel Aviv, enero-junio, 1994. 
En el contexto de la Revolución cubana, y cuando el conflicto por el "caso Padilla" y la influencia norteamericana habían alejado a la intelectualidad hispanoamericana de los ideales de dicha revolución, surge la obra de Roberto Fernández Retamar, mediante la cual se da la consolidación de Calibán como símbolo de América Latina. En Calibán. Apuntes sobre la cultura en nuestra América, Calibán sigue siendo el colonizado, pero es además el mestizo, elemento de cohesión ya anteriormente señalado por Martí. Por la vía etimológica Fernández Retamar intenta mostrar que Calibán es el Caribe, que puede tener dos aproximaciones, una que llama de derecha en la que la asociación es Caribe-Calibán-caníbal, con un sentido peyorativo; la otra, de izquierda, es la asociación Caribe-taíno, criatura edénica, con sentido utópico.

A partir de este momento se define de manera categórica la triangulación Próspero-Ariel-Calibán:

Asumir nuestra condición de Calibán implica repensar nuestra historia desde el otro lado, desde el otro protagonista. El otro protagonista de La tempestad (o, como hubiéramos dicho nosotros, El ciclón) no es por supuesto Ariel, sino Próspero. No hay verdadera polaridad Ariel-Calibán: ambos son siervos en manos de Próspero, el hechicero extranjero. Sólo que Calibán es el rudo e inconquistable dueño de la isla, mientras que Ariel, criatura aérea, aunque hijo también de la isla, es en ella, como vieron Ponce y Césaire, el intelectual. ${ }^{18}$

En esta estructuración del complejo simbólico hay entonces una nueva inversión de los símbolos. Próspero representa al colonizador: Europa, Estados Unidos, el imperialismo, el intervencionismo e inclusive el cosmopolitismo que amenaza al nacionalismo y a la pretendida unidad latinoamericana. Calibán es América Latina, mestiza, es cierto, pero que reconoce más sus raíces en el conquistado, el nativo, el dueño original de la isla; y es la América Latina revolucionaria, porque Calibán no es el colonizado sumiso de Mannoni, sino el inconquistable. Ante esto, Ariel es el intelectual que debe elegir entre Próspero y Calibán.

${ }^{18}$ Fernández Retamar, op. cit., p. 100. 
Habla Retamar de la existencia de dos tipos de cultura en América Latina: la "genuina", aquella gestada por el pueblo mestizo, la de las clases explotadas, la pequeña burguesía, el campesinado y la clase obrera, que es una cultura en constante construcción y que posee rasgos propios aunque haya nacido de una síntesis, pues no se limita a repetir los rasgos de los elementos que la compusieron; y la cultura de la antiAmérica, la de los opresores, de quienes tratan de imponer o reproducir esquemas ajenos y que con ello traicionan - de acuerdo con la afirmación de Martínez Estrada que cita Retamar - la causa de la verdadera emancipación de la América Latina.

Pero como muestra Klengel, ésta es sólo una parte de la lectura de $\mathrm{Ca}-$ libán. Otra es que mediante la esencial cita de Shakespeare en la que Calibán usa la lengua que Próspero le ha enseñado para maldecirlo, y al aceptar Retamar que él mismo está discutiendo con la lengua y las herramientas conceptuales del colonizador, que ya son también suyas, define al complejo sujeto de su propia identidad cultural mixta (mestiza). Así, al describir el cambio de significación del símbolo shakesperiano se coloca a sí mismo en una tradición diferente. La estrategia retórica consiste en la combinación de una historia de conceptos y motivos de Calibán no-europeos (Caribe-caníbal-Calibán), y la identificación con el símbolo mismo, que sí lo es. Con ello, Fernández Retamar explicita el derecho a una interpretación diferente de un modelo originalmente europeo, lo cual es un "verdadero gesto subversivo de apropiación" que le ayuda a legitimar la cultura latinoamericana como una América mestiza. ${ }^{19}$

La idea de la identidad latinoamericana permanece, pero ahora está fundamentada en elementos muy distintos de los que originalmente había propuesto Rodó. El enemigo común sigue siendo Estados Unidos, pero ya no es el único, ahora lo es también cualquier intento de colonización,

${ }^{19}$ Susanne Klengel, "From 'cultural cannibalism' to metalinguistic novel-writing ", Intellectual News. Review of the International Society for Intellectual History, núms. 67 (2000), p. 5.

En http://www.fu-berlin.de/lai/aktuelles/Caliban-Ariel-RV.pdf [Consulta: diciembre, 2003]. 
cualquier imperialismo, ya sea económico, político o cultural. Y el elemento de cohesión ya no es la herencia hispánica en sí misma, sino el resultado de ésta en síntesis con el habitante nativo, es decir, la raza mestiza. Ésta es una postura mucho más incluyente que la de Rodó, pues el concepto mismo de mestizaje implica ya una heterogeneidad del producto de la síntesis que cuestiona la "homogeneización civilizatoria" ${ }^{20}$

Ya no se trata únicamente de la imposibilidad o infructuosidad de trasladar a América Latina los modelos norteamericanos, sino de la posibilidad concreta de generar los propios modelos, aun cuando se utilicen instituciones, categorías y sistemas políticos, económicos o axiológicos ajenos. La herramienta, desde luego, el socialismo, pero no por la mera imitación del socialismo en curso, sino mediante la formulación de uno propio cimentado en asumir la peculiar heterogeneidad. ${ }^{21}$ En este sentido, la idea de la identidad latinoamericana en Fernández Retamar ya no tiende a la eliminación de la diferencia en aras de los sistemas de valores y creencias heredados por la vía hispánica, no es una identidad uniformizante, sino una identidad que precisamente asume esa diferencia en un doble sentido: diferencia respecto al otro que pretende imponerse como modelo, diferencia por la condición sui generis totalmente irrepetible, pero también diferencia implícita dentro de eso que se es, en cuya heterogeneidad radica su originalidad y por lo tanto su identidad.

\section{¿EXISTE UNA IDENTIDAD LATINOAMERICANA?}

Conforme transcurría el siglo xx, la amenaza del expansionismo norteamericano se fue convirtiendo en una realidad que trascendió los límites de Latinoamérica y comenzaron a sentirse los estragos de la Guerra Fría. En la mayoría de los países latinoamericanos se vivió una profunda inestabilidad política, que en muchos casos terminó en guerras civiles, golpes

${ }^{20}$ Yamandú Acosta, "Globalización e identidad latinoamericana”, Página latinoamericana de filosofía, núm. 3 (1997).

En http://www.ngweb.com/latinofil/nrotres/3global.html [Consulta: diciembre, 2003].

${ }^{21}$ Ibid., p. 5. 
de Estado y dictaduras. Como es evidente, cada uno de estos países tuvo sus propios procesos y vivió su propia historia, pero de una forma u otra el brazo norteamericano se podía percibir en cada uno de dichos procesos. Esto contribuyó a consolidar y acrecentar la idea de que "la formidable república del Norte" era el enemigo casi invencible, que en aras de sus intereses económicos estaba dispuesto a intervenir en la política de todos los países latinoamericanos, sin respetar su autodeterminación y sin favorecer su desarrollo.

Al mismo tiempo, la pregunta por la identidad latinoamericana continuaba; ya para la segunda mitad del siglo Xx esta búsqueda se intentó asociar con proyectos políticos concretos, aunque en general la mayor parte de los países latinoamericanos continuaron aplicando modelos liberales y desarrollistas, ya fuera por convicción propia o por imposición de ciertos grupos, por lo general relacionados con los intereses económicos internacionales. En términos generales y a pesar de la existencia de importantes excepciones como Cuba y el gobierno de Salvador Allende en Chile, puede decirse que los gobiernos latinoamericanos desarrollaron una política cada vez más cercana a Estados Unidos, llegando en algunos casos incluso al servilismo, aun cuando la idea de la identidad todavía se construía en oposición a ellos.

Poco a poco el problema de la identidad latinoamericana se fue haciendo más complejo, ya no sólo se cimentaba en una herencia compartida, manifestada en la lengua, la religiosidad y los valores espirituales. Ahora se cuestionaba la existencia misma de la identidad, sus condiciones de posibilidad, se fue aceptando y asumiendo la diversidad, de modo que la idea de identidad se fue acercando cada vez más a la condición de un referente utópico, aunque también hubo quien la daba como un hecho. Esto implicó que la idea de identidad fuera adquiriendo más bien tintes de unidad, es decir, que dejara de cimentarse en las bases históricas concretas de Rodó, en el pasado, y recobrara su condición de opción a futuro, de utopía, que no negara las particularidades nacionales, sino que lograra una unión de los diversos pueblos latinoamericanos para hacer frente a los embates de las grandes potencias. 
Muchos intelectuales latinoamericanos dedicaron una parte importante de sus esfuerzos a analizar el problema de la identidad. Uno de los más críticos al respecto fue siempre Edmundo O'Gorman, quien consideraba que el innegable tronco común del pasado latinoamericano no era operante para hablar de una efectiva unidad entre los países que surgieron a partir de las independencias, pues sostiene que justamente ese pasado común fue lo que propició la separación de las diferentes entidades nacionales; en oposición a lo que ocurrió con las disímiles colonias norteamericanas, que no fundaron su unidad en su pasado, sino en su futuro común..$^{22}$ Esta separación dio lugar al surgimiento de los nacionalismos, de modo que la identidad una vez más desplazó sus referentes y los trasladó de la cultura y la raza a la tierra, al lugar de nacimiento, apareciendo así las culturas matrioteras de las que habla Gabriel Zaid, y esta vinculación al terruño que se definió después de las independencias fue la causa de que no se lograra construir una identidad y un futuro común latinoamericano. ${ }^{23} \mathrm{Al}$ cimentarse los nacionalismos en cuestiones territoriales, encuentran elementos para diferenciarse de aquellos que podrían ser sus iguales en los ámbitos cultural y racial, generando así las distancias que impidieron la consolidación de la identidad de los países latinoamericanos independientes.

Por otra parte, O’Gorman critica la intención de buscar la "verdadera" identidad de Latinoamérica desde una perspectiva esencialista, pues sostiene que quien se pregunta por su identidad es porque de algún modo sabe lo que es pero esto por alguna razón no le satisface, por lo que intenta buscar otro modo de ser que sí lo haga y sobre el cual no quepa ninguna duda. Por ello, Latinoamérica debe asumir que no puede tener más identidad que la que tiene, la cual es completamente histórica, es decir, indisolublemente ligada al devenir de sus pueblos. Buscar una "verdadera identidad" fundamentada en posturas idealistas y míticas, como lo hizo Rodó, sólo lleva a exacerbaciones e impide asumir que ese

${ }^{22}$ O’Gorman, op. cit., passim y “Latinoamérica: Aí no”, Nexos, núm. 123, México, 1988.

${ }^{23}$ Gabriel Zaid, Cómo leer en bicicleta, México, Joaquín Mortiz, 1979. 
pasado común lo único común que ha generado es la frustración e insatisfacción respecto al modo de ser heredado, y que por lo tanto, dicha idea debe superarse para asumir las circunstancias actuales y construir un programa a futuro cimentado en bases más realistas. ${ }^{24}$

No todas las posturas acerca de la identidad latinoamericana han sido tan críticas y radicales como las de O'Gorman; por ejemplo, Octavio Paz sostenía que la identidad latinoamericana es evidente, y se expresa constantemente en un poema, una novela, una crónica o unas páginas de historia; pero al ser plural y cambiante, es decir, al tratarse de un proceso sometido a las leyes de la historia y de la geografía y estar en perpetuo movimiento no puede reducirse a una articulación de conceptos, pero ello no quiere decir que no exista, pues para él, la cultura latinoamericana es una por el origen y la evolución de las sociedades que la componen, y esa unidad, como ya se dijo, se percibe en destellos de la crea ción humana. A pesar de reconocer la dificultad para definir esa identidad, Paz considera que se debe continuar buscándola, que es importante seguir preguntándose por ella, y no sólo porque la pregunta sea valiosa en sí misma, sino porque los resultados que se obtienen de la pregunta son justamente los que expresan dicha identidad, aun cuando no se logre responderla. ${ }^{25}$

Por su parte Luis Villoro se hace esta misma pregunta, pero relacionando los elementos históricos (económicos, políticos, sociales y culturales) con la situación de América Latina en el momento de su análisis (1987), la actualiza, y hace explícito el carácter de referente utópico de la unidad latinoamericana, en el sentido de que si bien existen elementos para encontrar un pasado compartido que vincule a estos países, lo más importante es hacer un frente común para resistirse a la amenaza que significa la Guerra Fría y el constante intervencionismo. Es decir, en Villoro la identidad latinoamericana vuelve a verse, al igual que en Rodó, como un proyecto, que ya no sólo es cultural sino que es a la vez político y

${ }^{24}$ O’Gorman, "Latinoamérica...”, pp. 13-14.

${ }^{25}$ Octavio Paz, "Política cultural o cultura política”, Vuelta, núm. 136, México, 1988. 
económico, para enfrentar la amenaza que implica el intervencionismo y los intereses de las grandes potencias mundiales. El punto más importante en Villoro es la vinculación con la situación que se vivía en América Latina en ese momento. Parecería como si se repitiera la historia - o más exactamente quizá no había cambiado-, y de nuevo las condiciones históricas fueran el motor que hiciera evidente la necesidad de unirse para defenderse de la amenaza exterior. Villoro señala con claridad: "sólo si el anhelo espiritual se acompaña de un interés histórico específico, la imagen utópica puede convertirse en proyecto político;" ${ }^{26}$ es decir, como en Rodó, las circunstancias históricas concretas son el elemento que otorga la fuerza para que la utopía se pueda, y se deba, convertir en realidad y trascender el ámbito de las ideas.

\section{A MÁS DE CIEN AÑOS DE ARIEL}

Ese interés histórico específico del que habla Villoro quizá sea aún más evidente en la actualidad. Los embates de la globalización no son sólo cada vez más claros, sino también más ineludibles. Por eso ahora lo que muchos intelectuales, y ya no sólo latinoamericanos, se preguntan es si tiene sentido seguir buscando una identidad justo cuando el avance de los medios masivos de comunicación, del mercado mundial y de los intereses económicos tienden a la destemporalización, la desterritorialización y la desaparición de las formas particulares de ser en aras del modelo unificador de las grandes potencias mundiales y en especial de Estados Unidos. Además de todo esto, la afirmación y reivindicación de la diversidad han puesto en cuestión los referentes monosimbólicos para representar la complejidad de cualquier realidad.

Desde ese punto de vista, muchas nuevas lecturas, críticas, reivindicaciones y resignificaciones tanto de Ariel como de Calibán han surgido en los contextos más diversos y dentro de múltiples campos de análisis.

\footnotetext{
${ }^{26}$ Luis Villoro, "La idea de la unidad iberoamericana", en ibid., p. 55.
} 
Algunos autores han realizado comparaciones entre la situación latinoamericana de finales del siglo XIX que dio origen a Ariel y la situación actual en la que puede realizarse una relectura del mismo. Por ejemplo, Fernando Aínsa, en "Ariel, una lectura para el año 2000", considera que existen varias similitudes entre las dos épocas, entre ellas sobre todo la sensación de crisis de valores y la agigantada figura de los estadounidenses y su persistente intervención en la vida latinoamericana. Señala que Rodó comprendió que no bastaba con lamentarse y que era necesario intentar dar una respuesta al pesimismo y decadentismo que reinaba en su época, y considera que esto es igualmente necesario en la actualidad, por lo que propone cuatro puntos que considera vigentes de la obra de Rodó: su espíritu crítico, desconfiado de plataformas concretas y de programas que fijaran un sistema de ideas, lejano del dogmatismo y que proponía la constante renovación del pensamiento, orientado siempre hacia el porvenir; su carácter ecléctico que busca conjugar los extremos entre los que oscila la razón humana — el fanático y el escéptico — para sintetizar los rasgos de un carácter superior en el que se conjuguen el ideal creativo, el entusiasmo dotado de tolerancia y la curiosidad por los ideales ajenos; su vinculación de ética y estética; y su americanismo como programa de liberación. Estos cuatro puntos siguen proporcionando opciones a la América Latina de la actualidad, que más de 100 años después no ha visto aparecer una obra capaz de semejar el impacto y la influencia del Ariel. $^{27}$

Por su parte, Yamandú Acosta hace un profundo análisis sobre la pertinencia de Calibán como símbolo de América Latina, y la posibilidad de la idea de identidad latinoamericana en plena globalización; señala que la cuestión de la identidad cultural latinoamericana no es un dato empírico sino un referente utópico, en el sentido de que ha estado presente en el ámbito discursivo, desde Bolívar, como algo que se debe “construir”. Analiza por lo tanto la función utópica de Ariel y Calibán

${ }^{27}$ Fernando Aínsa, “Ariel, una lectura para el año 2000”, en Ette y Heydenreich, op. cit., pp. 41-57. 
para dar cuenta de las significaciones y resignificaciones de estos símbolos en términos de construcción de identidad. Cuestiona las posturas que niegan vigencia a Calibán como símbolo de identidad de América Latina, y aunque reconoce que carece de funcionalidad para representar la diversidad de identidades en el espacio cultural posmoderno consideradas en su diferencia, que no es representativo de los sectores socioculturales que habitan en los márgenes de la "ciudad letrada" y que no puede ser resignificado desde la mujer o desde las minorías raciales o sexuales, si es visto como referente utópico, funciona para combatir el paralizante realismo pragmático, porque al poner en juego lo imposible permite imaginar, pensar y realizar lo posible.

En esta perspectiva, Calibán no es un referente empírico actual, ni una meta empírica a alcanzar, sino un referente utópico para la construcción de un proyecto que tiene que contrarrestar la «deshistorización» y la «desterritorialización» de la globalización en curso, por la reconstrucción de los parámetros tempo-espaciales como ejes de sentido cultural auténtico y autónomo. [...] Calibán puede simbolizar hoy de un modo renovado, un proyecto cultural contrahegemónico alternativo dotado de validez, en tanto puede sostenerse que «es valioso que sea». ${ }^{28}$

Para él, Calibán sigue vigente entonces porque legitima la autoconstrucción de la diferencia frente a la globalización y la homogeneización y orienta el pensamiento y la acción hacia un futuro distinto del que de éstas se deriva.

Finalmente, Nadia Lie, con su crítica a la lectura poscolonial que se ha hecho de Calibán, — que la entiende como una meditación sobre los problemas de raza y que atribuye al término mestizo elementos como imprevisibilidad e hibridez que no estaban en el sentido original-, muestra que el poscolonialismo ha traducido la obra desde sus propias preocupaciones y en sus términos, extrayéndola de su contexto e intención, de modo que todo su sentido anticolonialista se diluye en un discurso

${ }^{28}$ Acosta, op. cit. 
opuesto, poscolonialista. ${ }^{29}$ Con ello nos hace recordar que aunque las diversas interpretaciones son válidas, no debe perderse el referente textual e histórico que da sentido a un símbolo. Y es precisamente ése el que se intentó delinear en este ensayo.

\section{CONSIDERACIONES FINALES}

Como habrá podido verse con lo hasta ahora señalado, la idea de la identidad latinoamericana dista mucho de ser homogénea, como tampoco lo son esos pueblos que se ha pretendido agrupar bajo el complejo simbólico de La Tempestad de Shakespeare. Asimismo, puede verse que la búsqueda de identidad es completamente histórica, es decir, ha cambiado su carga semántica de acuerdo con el momento y los acontecimientos que le han dado sentido. Así, puede decirse que lo que con Rodó nació con un contenido cultural, como una identidad "patriotera" poco a poco se fue resignificando, adquirió connotaciones raciales con Fernández Retamar y finalmente se convirtió en una identidad "matriotera", ligada a la tierra, al lugar de origen, y dio cabida a los nacionalismos que, lejos de favorecer, impidieron el desarrollo de una identidad común latinoamericana. Es claro que estos tres elementos han estado profundamente imbricados todo el tiempo en la pregunta por la identidad, pero dependiendo de cuál se ha privilegiado, de acuerdo con las necesidades históricas, es el sentido que ha ido adquiriendo.

En este ensayo se revisaron algunas de las posturas principales que se dieron a lo largo del siglo xx en torno a la identidad latinoamericana, así como los desplazamientos que sufrieron sus referentes simbólicos shakesperianos, y pudo verse cómo se dio un cambio de valoración que

${ }^{29}$ Nadia Lie, "Translation studies and the other canníbal: the English versión of Fernández Retamar's Calibán”, Enter text, núm. 2-2, 2003.

En http: //www.brunel.ac.uk/faculty/arts/Enter text/2.2.pdfs.lie.pdf [Consulta: diciembre, 2003]. 
fue desde la herencia clásica y la cultura de élite simbolizada en Ariel hasta los elementos que se consideran más cercanos a la realidad latinoamericana como el mestizaje y la heterogeneidad cultural representados por Calibán, de modo que la idea de identidad pasó a ser más bien un deseo de unidad basado en la necesidad de defender lo que somos, cualquiera que sea el significado de esto, frente al avance de aquello contra lo que siempre nos hemos defendido, o de aquello que justamente no somos: Estados Unidos.

Es indudable que el mundo se encuentra en la actualidad en una situación ambivalente en la que desde "la ciudad letrada" se ha intentado dar voz a las diferencias que hasta hace muy poco tiempo no la habían tenido; que inmersos en plena "condición posmoderna", la muerte de los grandes relatos implica la decadencia de los discursos homologadores y homogeneizantes, que tienden simplemente a sobrevalorar los sistemas de creencias y valores de los grupos hegemónicos con la intención de hacer invisibles a todos los que disienten de ellos; pero por otra parte, la realidad habla de un cada vez más extendido sistema homologador, que bajo el optimista término de globalización oculta la realidad de una norteamericanización cada vez más profunda que se percibe en todos los ámbitos de la vida. El predominio de los intereses económicos en los procesos de globalización ha hecho que ésta, lejos de ser una realidad de intercambio y multiculturalidad se convierta en una adopción casi absoluta de los patrones de vida norteamericanos.

En este sentido, cabe destacar que el arielismo surgió en un momento clave para la historia de la América hispana; emergió como una posible respuesta a la situación casi desesperada que enfrentaba un grupo de países que se sentía inevitablemente amenazado por un poder que se veía y se imaginaba gigante, y al que no se sabía como combatir. Curiosamente, nació como una utopía y más de cien años después vuelve a ser eso que fue en un principio, un referente, un ideal quizá inalcanzable pero que puede seguir sirviendo como inspiración, como fuerza para contrarrestar aquella amenaza que desgraciadamente (ineludible el juicio de valor) casi se ha convertido en una realidad. La globalización, la homogeniza- 
ción, los medios masivos de comunicación han logrado que se desdibuje cada vez más el individuo, que se pierdan los referentes de tiempo y espacio, y por qué no decir con Rodó, que se olvide la espiritualidad. Es cierto que cada vez son más los gritos que emergen de todas partes denunciando, preguntando, criticando, proponiendo, pero la amenaza avanza y se hace cada vez más palpable.

Es claro que el principal peligro sigue estando dentro de esa "América nuestra" que no ha renunciado a su nordomanía y que lucha desesperadamente por insertarse en un mundo que sólo tiene para ella un sitio de subordinación. Por eso quizá una respuesta siga estando en Ariel y en Calibán, ¿por qué renunciar al sueño de hacer un frente común? Pero no hay que perder la brújula, ese frente común hace mucho tiempo que ya no quiere decir construir una identidad que elimine la diferencia, y menos ahora que esas diferencias comienzan a encontrar un sitio propio desde el cual hablar de sí mismas.

Es cierto que los elementos tradicionales del discurso de identidad están en crisis, pero eso no implica que la pregunta deje de tener sentido. El problema es permitir la momificación de la identidad queriéndola cimentar en conceptos dados de una vez y para siempre, en vez de asumir que la identidad y la cultura son algo dinámico, en permanente construcción.

Por eso en el centro del debate sigue estando el intelectual, que desde la "ciudad letrada" dirime las hegemonías culturales e intenta consolidar un imaginario colectivo. ${ }^{30}$ Pero ese Ariel tiene ahora ante sí un compromiso mucho más grande que el de hace cien años, pues debe lidiar desde la diversidad para encontrar elementos de cohesión que le den fuerza. Y parece imposible entonces no tomar postura, no verse como un ser actuante que incide de manera efectiva en el acontecer de su tiempo, sin que ello implique ninguna megalomanía. Es simplemente que se coincide con Fernández Retamar en que el intelectual debe ser combatiente

${ }^{30}$ Acosta, op. cit. 
(que no necesariamente militante), comprometerse con su aquí y ahora, y ejercer a toda costa su libertad para proponer su proyecto cultural.

Las preguntas que se hacen hoy al complejo simbólico shakesperiano son tan diversas como lo es el mundo que se las hace. Y como intentó señalarse al comienzo de este trabajo, quizá más que las respuestas, lo que sea capaz de hablar de nosotros mismos y hacernos visibles sean las preguntas; por ello, mientras siga existiendo quien tenga algo que preguntarle a Ariel, a Calibán o a Próspero, éstos seguirán vigentes como símbolos de "Nuestra América".

BIBLIOGRAFÍA

Abellán, José Luis, "Modernismo: Ariel como símbolo", Anales del Seminario de Historia de la Filosofía, núm. 17, Madrid, 2000, pp. 219-229.

Acosta, YAmAndú, "Globalización e identidad latinoamericana", Página latinoamericana de filosofia, núm. 3, 1997. En http://www.ngweb.com/ latinofil/nrotres/3global.html [Consulta: diciembre, 2003].

Bernecker, WALther L., "El fin de siglo en el Río de la Plata: intereses internacionales y reacciones latinoamericanas", en Ottmar Ette y Titus Heydenreich [eds.], José Enrique Rodó y su tiempo. Cien años de Ariel, Frankfurt/Madrid, Vervuet/Iberoamericana 2000.

BRADING, DAVID, Los orígenes del nacionalismo mexicano, trad. de Soledad Loaeza, México, Era, 1980, 138 pp.

Brotherston, Gordon, "Introducción a Ariel, de J. E. Rodó (II). Prólogo a la edición de Ariel de la Cambridge University Press, 1967”. En Enciclopedia, Uruguay, trad. de Aldo Mazzucchelli. En http:// www.henciclopedia.org.uy/autores/Brotherston/Rodo\%20(II).htm [Consulta: diciembre, 2003].

Cheroni, Alción, "La revolución cultural positivista en el Uruguay" Galileo, núm. 22, 2000. 
En http://galileo.fcien.edu.uy/la_revolucion_cultural_positivista_uruguay.htm [Consulta: diciembre, 2003].

Centro Coordinador y Difusor de Estudios Latinoamericanos, Diccionario de Filosofía Latinoamericana. Biblioteca virtual Latinoamericana, México.

En http://www.ccydel.unam.mx/pensamientoycultura/biblioteca\%20virtual/Diccionario [Consulta: diciembre, 2003].

DARío, RuBÉN, “El triunfo de Calibán”, Proyecto ensayo hispánico, Georgia.

En http://ensayo.rom.uga.edu/antologia/XIXa/dario/ [Consulta: diciembre, 2003].

, Poesías completas. Libros poéticos completos y antología de la obra dispersa, estudio preliminar de Enrique Anderson Imbert, México, FCE, 1984, 510 pp. (Biblioteca Americana, Serie de literatura moderna, Vida y Ficción).

Ette, Ottmar y Titus Heydenreich [eds.], José Enrique Rodó y su tiempo. Cien años de Ariel, Frankfurt/Madrid, Vervuet/Iberoamericana, 2000, $231 \mathrm{pp}$.

Fernández Retamar, RoBerto, "Calibán revisitado", La jiribilla. Revista de la cultura cubana, núm. 80, 2002. Libro digital Todo Calibán. En http://www.lajiribilla.cu/pdf/caliban2.pdf [Consulta: diciembre, 2003].

, "Calibán en esta hora de nuestra América", La jiribilla. Revista de la cultura cubana, núm. 80, 2002. Libro digital Todo Calibán. En http://www.lajiribilla.cu/pdf/caliban2.pdf [Consulta: diciembre, 2003]. , “Calibán quinientos años más tarde", La jiribilla. Revista de la cultura cubana, núm. 80, 2002. Libro digital Todo Calibán. En http:/www.lajiribilla.cu/pdf/caliban3.pdf [Consulta: diciembre, 2003].

Fuentes, CARlos, El espejo enterrado, México, FCE, 1994, 440 pp. (Colección Tierra Firme). 
Gracia NoriEgA, José IGNACIO, "Una lectura: Renan o las fronteras históricas”, La ilustración liberal, núm. 8, abril, 2001, Madrid. En http://www.libertaddigital.com:83/ilustracion_liberal/articulo.php/14 5 [Consulta: diciembre, 2003].

Hernández, Conrado, "Edmundo O'Gorman y el liberalismo mexicano", Metapolitica, vol. 7, núm. 31, México, septiembre/octubre, 2003, pp. 100-111.

JÁuregui, CARlos, “Calibán: ícono del 98. A propósito de un artículo de Rubén Darío”, Proyecto ensayo hispánico. Georgia.

En http://ensayo.rom.uga.edu/filosofos/nicaragua/dario/Jauregui.htm [Consulta: diciembre, 2003].

, "Arielismo e imaginario indigenista en la Revolución boliviana. Sariri: una réplica a Rodó (1954)," Revista de crítica literaria latinoamericana, núm. 59, año XXX, $1^{\text {er }}$ semestre, 2004, pp. 155-182.

Klengel, Susanne, “From 'cultural cannibalism' to metalinguistic novel-writing", Intellectual News. Review of the International Society for Intellectual History, núms. 6-7, 2000. En http://www.fuberlin.de/lai/aktuelles/Caliban-Ariel-RV.pdf [Consulta: diciembre, 2003].

Kovadloff, Santiago Ezequiel, "Por un futuro imperfecto", Vuelta, núm. 136, México, 1988.

LEGRÁs, HorACIO, “Criollismo e indigenismo literarios: representación sin resto y resto sin representación”, Georgetown University. Colaboración para Mario Valdés, Linda Hutcheon y Djelal Kadir [coords.], Latin American Literatures: A Comparative History of Cultural Formations, vol. 3 [en prensa].

En http://www.georgetown.edu/faculty/hl/Toronto.htm [Consulta: diciembre, 2003].

LIE, NADIA, "Translation studies and the other cannibal: the English version of Fernández Retamar's Calibán”, Enter text, núm. 2.2, 2003. En http://www.brunel.ac.uk/faculty/arts/EnterText/2_2_pdfs/lie.pdf [Consulta: diciembre, 2003]. 
MARTí, José, "Nuestra América”, en Roberto Hernández Montoya, Bitblioteca, Caracas. En http://www.analitica.com/bitblioteca/jmarti/nuestra_america.asp [Consulta: diciembre, 2003].

NuÑO, JuAN, "Latinoamérica: variedad y divergencia”, Vuelta, núm. 136, México, 1988.

O'Gorman, Edmundo, México: el trauma de su historia, México, unam, 1977, 119 pp.

, “Latinoamérica: Así no", Nexos, núm. 123, México, 1988.

Paz, Octavio, "Política cultural o cultura política", Vuelta, núm. 136, México, 1988.

Perilli, CARMEN, "Mestizaje y Arielismo en la escritura de Carlos Fuentes", Espéculo, núm. 23, Madrid, 2003.

En http://www.ucm.es/info/especulo/numero23/mestizaj.html [Consulta: diciembre, 2003].

Ramos, Samuel [selec. y pról.], Rodó, México, SeP, 1943, 171 pp. , Ariel/Fernández Retamar, Roberto, Calibán. Apuntes sobre la cultura en nuestra América, pról. y notas de Abelardo Villegas, México, SEP/UNAM, 1982.

Rodríguez Monegal, Emir, "Las metamorfosis de Calibán”, Vuelta, vol. 3, núm. 25, México, diciembre, 1978, pp. 23-26.

. "El maestro de la Belle Epoque", Lisa Block de Behar, Archivo de prensa, Uruguay. En http://mll.cas.buffalo.edu/rodriguez-monegal/bibliografia/prensa/artpren/iberoamer/latino_02.htm [Consulta: diciembre, 2003].

Shakespeare, William, Comedias: El mercader de Venecia, Como gustéis, noche de reyes, La tempestad, estudio preliminar de Ezequiel Martínez Estrada, trad. de Jaime Clark, Buenos Aires, W. M. Jackson Inc., 1950, 369 pp., (Serie Clásicos Jackson, 16).

Solari, Herminia, "Esteticismo moralizante en el Ariel de Rodó", Proyecto Arjé. Comunidad filosófica interdisciplinaria, Montevideo. En http://arje.uy.nu/ [Consulta: 21 de febrero, 2007].

TANI, RUBÉN, "Producción simbólica en la comunidad intelectual uruguaya: José Enrique Rodó (1871-1917)", Proyecto Arjé. Comunidad 
filosófica interdisciplinaria, Montevideo. En http://arje.uy.nu/ [Consulta: 21 de febrero, 2007].

VAldÉs Ugalde, Francisco, "Jano contra el Coloso del Norte", Fractal, año VI, vol. 6, núm. 22, México, otoño, 2001, pp. 133-178.

Vasconcelos, José, Ulises Criollo, 2 vols., México, FCE, 1983 (Serie Lecturas Mexicanas, 11 y 12).

VILloro, LuIs, "La idea de unidad iberoamericana", Vuelta, núm. 136, México, 1988.

WeINBerg, LilianA, "La identidad como traducción. Itinerario del Calibán en el ensayo latinoamericano", Estudios interdisciplinarios de América Latina y el Caribe, vol. 5, núm. 1, Tel Aviv, enero-junio, 1994, pp. 21-35.

ZAID, GABRIEL, Cómo leer en bicicleta, México, Joaquín Mortiz, 1979, 196 pp. 